\title{
Prevalence of Carotid Artery Atherosclerosis Plaque in Systemic Lupus Erythematosus in Hasan Sadikin Hospital Bandung in 2017-2018
}

\author{
Irham Rasyid ${ }^{1}$, Syarief Hidayat ${ }^{2}$, Laniyati Hamijoyo ${ }^{1}$ \\ ${ }^{1}$ Department of Internal Medicine, Faculty of Medicine, Universitas Padjadjaran/Dr. Hasan Sadikin General Hospital \\ 2 Department of Cardiology and Vascular Medicine, Faculty of Medicine, Universitas Padjadjaran/Dr. Hasan Sadikin General \\ Hospital
}

\section{A R T I C L E I N F O}

\section{Keywords:}

Lupus Low Disease Activity

Atherosclerotic Plaque

Carotid Artery

\section{Corresponding author:}

E-mail address: hamijoyo@yahoo.com

All authors have reviewed and approved the final version of the manuscript.

https://doi.org/10.37275/IJR.v11i2.129

\section{A B S T R A C T}

Background Systemic Lupus Erythematosus (SLE) is an autoimmune disease involving many organs including the cardiovascular system such as accelerated atherosclerosis or premature atherosclerosis. Atherosclerotic plaque can cause coronary heart disease, ischemic stroke and peripheral arterial disease, which are the main causes of death in the world. The purpose of this study was to determine the prevalence of carotid artery atherosclerosis plaques in patients with SLE. Methods This research is a descriptive study with a cross-sectional design. Carotid artery atherosclerosis plaques in SLE patients were assessed by analysing results of carotid ultrasound examinations that were conducted in 2017-2018. The inclusion criteria of this study were SLE patients who had undergone carotid doppler ultrasound $\mathrm{B}$ mode examination on the carotid artery for the period of 2017-2018. The exclusion criteria in this study were SLE patients with a history of stroke, peripheral arterial disease, and significant coronary artery disease. Results This study involved 88 SLE patients who met the inclusion criteria. Results showed that there were 10 SLE patients $(11.4 \%)$ who had atherosclerotic plaques. SLE patients with atherosclerosis plaque were mostly in the age range of $35-44$ years $(16 \%)$ and $45-54$ years $(22.2 \%)$. There were 2 patients (15.3\%) with atherosclerotic plaque from a total of 11 patients had high triglyceride levels $(\geq 150 \mathrm{mg} / \mathrm{dL})$. Chi square analysis of lipid profiles (cholesterol, LDL, HDL, triglycerides) in patients with atheroclerotic plaque revealed not significant $(p>0.05)$. These findings could be caused by several factors, such as the small number of samples in this study and the nontraditional factors in the formation of atherosclerotic plaque as well as other traditional factors. Conclusion The prevalence of carotid artery atherosclerosis plaques in patients with SLE in Dr. Hasan Sadikin General Hospital in 2017-2018 is $11.4 \%$.

\section{Introduction}


Systemic lupus erythematosus (SLE) is a systemic autoimmune disease, which is characterized by extensive inflammation and immune system dysfunction that underlies a set of diverse clinical manifestations. ${ }^{1}$ The clinical manifestations that usually occur in patients with SLE ranges from constitutional manifestations such as fever and loss of appetite, to involve of multiple organs such skin, musculoskeletal, renal and brain, including cardiovascular. Cardiovascular system manifestations usually occur in the form of atherosclerotic plaque. ${ }^{2}$ Atherosclerosis is a multifactorial condition that involves arteries, characterized by deposit of inflammatory cells (macrophages, T lymphocytes), extracellular matrix, fat, proteoglycans, glycosaminoglycans, connective tissue in the arteries' intima. The process will eventually cause thickening and hardening of the artery walls, resulting in arterial stiffness and fragility. ${ }^{3,4}$ Atherosclerosis is one of the leading causes of death in the world which gives rise to coronary heart disease, ischemic heart, ischemic stroke, and peripheral arterial disease. ${ }^{5}$ In SLE patients, atherosclerotic plaque can occur in an early onset called accelerated atherosclerosis or premature atherosclerosis. ${ }^{6}$ The risk of accelerated atherosclerosis or premature atherosclerosis is increased in SLE patients five to eight times higher than non-SLE patients. ${ }^{7,8}$ Based on data reported by Manzi and colleagues, SLE women aged 35 to 44 years are 50 times more susceptible to myocardial infarction compared with non-SLE women of the same age range. ${ }^{9}$ The European Society of Cardiology (ESC) recommended, several options to diagnose atherosclerosis, such as Ankle-Brachial Index (ABI) and Duplex Ultrasound (DUS). A method of DUS called B-mode echography can detect arterial subclinical disease including carotid artery plaque atherosclerosis. ${ }^{10}$

The prevalence of atherosclerosis in SLE patients in Indonesia is still unknown, hence a study to find out the prevalence of atherosclerosis in SLE patients at Dr. Hasan Sadikin General Hospital was conducted. This research is expected to help provide information of atherosclerosis in SLE and further, early detection and complications of atherosclerotic plaque in SLE patients could be prevented.

\section{Methods}

This is a cross-sectional descriptive study and was conducted using secondary data taken in the Rheumatology Division of Internal Medicine Dr. Hasan Sadikin Bandung from 1 January 2017 to 31 December 2018. The subjects of this study were patients diagnosed with SLE who were enrolled in previous studies entitled "Atherosclerotic Plaque Correlation with Cognitive Disorders in Systemic Lupus Erythematous Patients". The inclusion criteria of this study were SLE patients who had undergone carotid Doppler ultrasound B mode on carotid arteries from 2017 through 2018. The exclusion criteria were SLE patients with a history of significant coronary artery disease which includes; (1) history of chest pain typical of angina, having a history of heart attack, or currently being treatment for coronary artery disease (CAD); (2) having signs of left or right heart failure based on physical examination; (3) myocardial infarction or ischemic heart disease based on electrocardiographic examination. Total sampling was used as the sampling method of this study.

Atherosclerotic plaque was determined by the existence of plaque on the left carotid artery, or right carotid artery or both as listed on the medical records. The collected data was then analyzed.

Ethical clearance of this study was obtained from the Ethics Committee of the Faculty of Medicine, University of Padjadjaran. Secondary data was then taken from the Rheumatology Division of the Internal Medicine Department Dr. Hasan Sadikin Bandung.

\section{Result}

Eighty-eight patients met the inclusion 
criteria and were all included in this study. Table 1 shows the characteristics of the study subjects in terms of gender, age, and duration of SLE. Eightyeight $(100 \%)$ patients in this study were female. Most of the SLE patients in this study were in the age range of 25-34 years, comprised of 29 patients (33\%) and most patients were found to have SLE for more than 5 years $(56.8 \%)$. Table 2 provides an overview of the presence of atherosclerotic plaque, with 78 patients $(88.6 \%)$ have no atherosclerotic plaque and 10 patients $(11.4 \%)$ have atherosclerotic plaques. Table 2 points the location of atherosclerotic plaque, with 2 patients $(20 \%)$ have atherosclerosis plaque in the left carotid artery, 5 patients (50\%) have atherosclerotic plaque in the right carotid, and 3 patients (30\%) have atherosclerotic plaque in both the left carotid artery and in the right carotid artery. Table 3 provides an overview of atherosclerotic plaques based on age groups. In the age group of 35-44 years, there were 4 patients $(16 \%)$ with atherosclerotic plaque out of a total of 25 patients. In the 45-54 years age group, there were 4 patients $(22.2 \%)$ with atherosclerotic plaque out of a total of 18 patients, and 1 patient
$(12.5 \%)$ with atherosclerotic plaques were found in the $>55$ years age group from a total of 8 patients. Table 4 provides an overview of atherosclerotic plaques based on lipid profiles (cholesterol, LDL, HDL, triglycerides). At the $\geq 200 \mathrm{mg} / \mathrm{dL}$ cholesterol level group there were 5 patients (20.8\%) with atherosclerotic plaque from a total of 24 patients.At the $\geq 150 \mathrm{mg} / \mathrm{dL}$ triglyceride levels group there were 2 patients $(15.3 \%)$ with atherosclerotic plaque from a total of 11 patients. Chi-square analysis test result on lipid profiles (cholesterol, LDL, HDL, triglycerides) was more than 0.05 . This result indicates that the data was not significant.

Table 1. SLE Patients Characteristics

\begin{tabular}{cc}
\hline \multicolumn{1}{c}{ Variables } & Cases $\mathbf{N}=\mathbf{8 8}(\%)$ \\
\hline Gender & $0(0)$ \\
$\bullet \quad$ Male & $88(100)$ \\
$\bullet \quad$ Female & \\
Age Groups & $8(9,1)$ \\
$\bullet \quad 18-24$ years & $29(33,0)$ \\
$\bullet \quad 25-34$ years & $25(28,4)$ \\
$\bullet \quad 35-44$ years & $18(20,5)$ \\
$\bullet \quad 45-54$ years & $8(9,1)$ \\
$\bullet \quad \geq 55$ years & \\
Duration of SLE & $0(0)$ \\
$\bullet \quad<1$ year & $38(43,2)$ \\
$\bullet \quad 1-5$ years & $50(56,8)$ \\
$\bullet \quad>5$ years & \\
Total Cholesterol & $64(72,7)$ \\
$\bullet \quad<200 \mathrm{mg} / \mathrm{dL}$ & $24(27,3)$ \\
$\bullet \quad \geq 200 \mathrm{mg} / \mathrm{dL}$ & \\
Low Density Lipoprotein (LDL) & $36(40,9)$ \\
$\bullet \quad<100 \mathrm{mg} / \mathrm{dL}$ & $52(59,1)$ \\
$\bullet \quad \geq 100 \mathrm{mg} / \mathrm{dL}$ & \\
High Density Lipoprotein (HDL) & $4(4,5)$ \\
$\bullet \quad<40 \mathrm{mg} / \mathrm{dL}$ & $84(95,5)$ \\
$\bullet \quad \geq 40 \mathrm{mg} / \mathrm{dL}$ & $75(85,2)$ \\
Triglycerides & \\
$\bullet \quad<150 \mathrm{mg} / \mathrm{dL}$ &
\end{tabular}


Table 2. Carotid Artery Atherosclerotic Plaque Characteristics in SLE Patients

\begin{tabular}{lc}
\hline \multicolumn{1}{c}{ Category } & Cases $\mathbf{N}=\mathbf{8 8}(\mathbf{\% )}$ \\
\hline Atherosclerotic Plaque (n=88) & \\
No plaque found & $78(88,6)$ \\
Plaque found & $10(11,4)$ \\
Plaque Location (n=10) & \\
Left Carotid Artery & $2(20)$ \\
Right Carotid Artery & $5(50)$ \\
Both Arteries & $3(30)$ \\
\hline
\end{tabular}

Table 3. Atherosclerotic Plaque Results by Age Group

\begin{tabular}{lccc}
\hline \multicolumn{1}{c}{ Age } & $\begin{array}{c}\text { Atherosclerotic } \\
\text { Plaque }\end{array}$ & $\begin{array}{c}\text { No Atherosclerotic } \\
\text { Plaque }\end{array}$ & Total \\
\hline 18-24 years & $0(0)$ & $8(100)$ & $8(100)$ \\
25-34 years & $1(3,4)$ & $28(96,5)$ & $29(100)$ \\
35-44 years & $4(16)$ & $21(84)$ & $25(100)$ \\
45-54 years & $4(22,2)$ & $14(77,7)$ & $18(100)$ \\
>55 years & $1(12,5)$ & $7(87,5)$ & $8(100)$ \\
\hline
\end{tabular}

Table 4. Atherosclerotic Plaque Results by Lipid Profiles

\begin{tabular}{ccccc}
\multicolumn{5}{c}{ Table 4. Atherosclerotic Plaque Results by Lipid Profiles } \\
\hline Category & $\begin{array}{c}\text { Atherosclerotic } \\
\text { Plaque }\end{array}$ & $\begin{array}{c}\text { No Atherosclerotic } \\
\text { Plaque }\end{array}$ & Total & P-Value \\
\hline $\begin{array}{c}\text { Cholesterol } \\
<200 \mathrm{mg} / \mathrm{dL}\end{array}$ & $5(7,8)$ & $59(92,2)$ & 64 & 0.87 \\
$\geq 200 \mathrm{mg} / \mathrm{dL}$ & $5(20,8)$ & $19(79,2)$ & $(100)$ & \\
& & & 24 & \\
& & & $(100)$ & \\
LDL & $4(11,1)$ & $32(88,8)$ & 36 & 0.46 \\
$<100 \mathrm{mg} / \mathrm{dL}$ & $6(11,5)$ & $46(88,5)$ & $(100)$ & \\
$\geq 100 \mathrm{mg} / \mathrm{dL}$ & & & 52 & \\
& & & $(100)$ & \\
HDL & $0(0)$ & $4(100)$ & $4(100)$ & 0.95 \\
$<40 \mathrm{mg} / \mathrm{dL}$ & $10(11,9)$ & 74 & 84 & \\
$\geq 40 \mathrm{mg} / \mathrm{dL}$ & & & $(100)$ & \\
& $8(10,6)$ & 67 & 75 & 0.62 \\
Triglycerides & $2(15,3)$ & 11 & $(100)$ & \\
$<150 \mathrm{mg} / \mathrm{dL}$ & & & 13 & \\
$\geq 150 \mathrm{mg} / \mathrm{dL}$ & & & $(100)$ & \\
& & &
\end{tabular}

\section{Discussion}

The patients in this study were found to be all female. This is in accordance with SLE research studies in Indonesia which has a 22:1 ratio between women and men. ${ }^{11}$ Results in this study showed that 10 patients (11.4\%) has atherosclerotic plaque, which is the symptom of coronary artery disease (CAD). This is in accordance with previous studies on the prevalence of SLE patients with atherosclerotic plaque, ranges from $6.6 \%$ in the Pitsburg study ${ }^{9}$ to $8.3 \%$ from the Baltimore cohort study ${ }^{12}$. SLE patients with the highest number of atherosclerotic plaques were in the age range of 35-44 years (16\%) and $45-54$ years $(22.2 \%)$. These results are in accordance with previous studies in the framingham off study, showing 
that SLE women with an age range of 35-44 years have a risk of getting myocardial infarction up to 50 times higher than non-SLE women with the same age range. ${ }^{9}$

Clinical manifestations in patients with SLE are very diverse, one of which affects the cardiovascular system in the form of atherosclerotic plaque. ${ }^{2}$ The formation of atherosclerotic plaque in SLE patients is influenced by several factors. In this study there is a description of atherosclerotic plaque based on age and lipid profile (cholesterol, HDL, LDL, triglycerides. Results of atherosclerotic plaque based on cholesterol level groups shows that at normal cholesterol levels <200mg / dl there are 5 patients $(7.8 \%)$ with plaque atherosclerosis, and at cholesterol levels $\geq 200 \mathrm{mg} / \mathrm{dl}$ there are 5 patients $(20.8 \%)$ with atherosclerotic plaque. Some studies suggested that increased cholesterol levels can increase the risk of atherosclerotic plaque formation. ${ }^{13}$

Results of atherosclerotic plaque based on LDL shows that there were 4 patients $(11.1 \%)$ with normal LDL level (<100 mg/dl) and had atherosclerotic plaque. There were 6 patients $(11.5 \%)$ with increased LDL level $(\geq 100$ $\mathrm{mg} / \mathrm{dl}$ ) and had atherosclerotic plaque. Previous studies showed that higher LDL levels in a person will increase the risk of atherosclerotic cardiovascular disease. ${ }^{14}$

Results of atherosclerotic plaque based on HDL shows that there were 0 patients $(0 \%)$ with low HDL level $(<40$ $\mathrm{mg} / \mathrm{dl}$ ) and had atherosclerotic plaques. There were 10 patients (11.9\%) with high HDL level ( $\geq 40 \mathrm{mg} / \mathrm{dl}$ ) and had atherosclerotic plaques. Previous studies mentioned that HDL levels in the body influences atherosclerotic plaque regression. 15

Results of atherosclerotic plaque based on triglycerides shows that there were 8 patients $(10.6 \%)$ with normal levels of triglycerides $(<150 \mathrm{mg} / \mathrm{dl})$ and had atherosclerotic plaques. There were 2 patients $(15.3 \%)$ with high levels of triglycerides ( $\geq 150 \mathrm{mg} / \mathrm{dl})$ and had atherosclerotic plaques. Previous studies showed that high triglycerides level increases the risk of atherosclerosis formation and its development. Triglycerides were found to promote the formation of foam cells, and subsequently the development of atherosclerosis plaque. ${ }^{16}$

Chi-square analysis test on all lipid profiles in this study was more than 0.05 , indicating that the data is not significant. These findings can be caused by several factors, such as the small number of samples in this study and the non-traditional factors in the formation of atherosclerotic plaque as well as the traditional factors.

The weakness of this study is the small number of samples, which causes the data to be insignificant when chi-square analysis test was performed. Other confounding factors need to be considered that can influence the result of this type of study.

\section{Conclusion}

The prevalence of carotid artery atherosclerosis plaque in patients with SLE in Dr. Hasan Sadikin General Hospital from 2017 to 2018 is $11.4 \%$.

\section{Acknowledgement}

The researcher is grateful to the SLE Study Group, the Center for Immunology Studies, Faculty of Medicine, Padjadjaran University, Bandung, for their assistance in completing the research data.

\section{References}

1. Pons-Estel GJ, Alarcón GS, Scofield L, Reinlib L, Cooper GS. Understanding the epidemiology and progression of systemic lupus erythematosus. Seminars in Arthritis Rheumatism. 2010;39(4):257-68.

2. Cojocaru M, Cojocaru IM, Silosi I, Vrabie CD. Manifestations of systemic lupus erythematosus. Maedica (Buchar). 2011;6(4):330-36.

3. Rafieian-Kopaei M, Setorki M, Doudi M, Baradaran A, Nasri H. Atherosclerosis: process, indicators, risk factors and new hopes. International Journal of Preventive Medicine. 2014;5(8):927-46.

4. Bergheanu SC, Bodde MC, Jukema JW. Pathophysiology and treatment of atherosclerosis : Current view and future perspective on lipoprotein modification treatment. Netherlands Heart Journal. 2017;25(4):231-42.

5. Barquera S, Pedroza-Tobias A, Medina C, et al. Global overview of the epidemiology of atherosclerotic cardiovascular disease. Archives of 
Medical Research. 2015;46(5):328-38.

6. Skaggs BJ, Hahn BH, McMahon M. Accelerated atherosclerosis in patients with SLE--mechanisms and management. Nature Reviews Rheumatology. 2012;8(4):214-23.

7. Croca S, Rahman A. Atherosclerosis in systemic lupus erythematosus. Best Practice and Research Clinical Rheumatology. 2017;31(3):364-72.

8. Schoenfeld SR, Kasturi S, Costenbader KH. The epidemiology of atherosclerotic cardiovascular disease among patients with SLE: a systematic review. Seminars in Arthritis Rheumatism. 2013;43(1):77-95.

9. Manzi S, Meilahn EN, Rairie JE, et al. Age-specific incidence rates of myocardial infarction and angina in women with systemic lupus erythematosus: comparison with the Framingham Study. American Journal of Epidemiology. 1997;145(5):408-15.

10. Task A, Members F, Aboyans V, et al. 2017 ESC Guidelines on the Diagnosis and Treatment of Peripheral Arterial Diseases, in collaboration with the European Society for Vascular Surgery ( ESVS ). European Heart Journal. 2018;39(09):763-21.

11. Hamijoyo L, Candrianita S, Rahmadi AR, Dewi S, Darmawan G, Suryajaya BS, et al. The clinical characteristics of systemic lupus erythematosus patients in Indonesia: a cohort registry from an Indonesia-based tertiary referral hospital. Lupus 2019;28:1604-9

12. Petri M, Spence D, Bone LR, Hochberg MC. Coronary artery disease risk factors in the Johns Hopkins Lupus Cohort: prevalence, recognition by patients, and preventive practices. Medicine (Baltimore). 1992;71(5):291-302.

13. Gotto Jr, Antonio M. Jeremiah Metzger Lecture: cholesterol, inflammation and atherosclerotic cardiovascular disease: is it all LDL? Transactions of the American Clinical and Climatological Association. 2011;122:256-89.

14. Ference BA, Ginsberg HN, Graham I, Ray KK, Packard KJ, Bruckert E, et al. Low-density lipoproteins cause atherosclerotic cardiovascular disease. 1.Evidence from genetic, epidemiologic, and clinical studies. A consensus statement from the European Atherosclerosis Society Consensus Panel. European Heart Journal. 2017;38(32):2459-72

15. Feig JE, Feig JL, Dangas GD. The role of HDL in plaque stabilization and regression: basic mechanisms and clinical implications. Coronary Artery Disease. 2016;27(7):592-603

16. Borge G. Triglyceride-Rich Lipoproteins and Atherosclerotic Cardiovascular Disease. Circulation Research. 2016;118(4):547-63. 